\title{
Fate of Nitrosodimethylamine (NDMA)
}

\author{
K. Jahan ${ }^{1}$, R. Smith ${ }^{1}$, D. Scrivani ${ }^{1}$, D. Giacobbe ${ }^{1}$, \\ J. McDonough ${ }^{1}$ \& A. Addu ${ }^{2}$ \\ ${ }^{1}$ Civil and Environmental Engineering, Rowan University, USA \\ ${ }^{2}$ Chemical Engineering, Rowan University, USA
}

\begin{abstract}
Nitrosodimethylamine (NDMA) is a known animal carcinogen and is noted as a probable human carcinogen by the USEPA with a lifetime risk of contracting cancer of $10^{-6}$ at $0.7 \mathrm{ng} / \mathrm{L}$. This contaminant is of rising concern since its production is linked to disinfection processes at water and wastewater treatment plants. The formation of NDMA is also associated with the production of rocket fuel. Therefore, a need to develop an effective treatment process to remove NDMA from water is needed. Batch experiments were conducted to determine the biodegradability and photodegradation of NDMA at varying concentrations. Biodegradation experiments were conducted with a mixed bacterial culture obtained from a wastewater treatment plant. Oxygen uptake and cell growth was monitored with time. Results indicated that NDMA was biodegradable with some inhibition at higher concentrations. Batch photodegradation experiments were carried out in the presence and absence of titanium dioxide $\left(\mathrm{TiO}_{2}\right)$ a common catalyst used to accelerate photodegradation. The removal of NDMA using photodegradation appears to be a feasible method. Initial removal rates are high. Lower $\mathrm{pH}$ and the addition of titanium dioxide accelerated the removal of NDMA. During the degradation of NDMA, by-products such as dimethylamine (DMA), formaldehyde, and nitrate were produced and remained at nearly constant concentrations.
\end{abstract}

Keywords: NDMA, biodegradation, photodegradation, UV radiation.

\section{Introduction}

In recent years, there has been growing concern about the presence of $N$ Nitrosodimethylamine (NDMA) in drinking water and soil [1]. NDMA has been 
listed as a potential human carcinogen and a known animal carcinogen. The USEPA does not list a regulatory limit on the concentration of NDMA in drinking water. However, the California Office of Environmental Health Hazard Assessment has recently set a draft public health goal of three ng/L [1].

The formation of NDMA is associated with the production of rocket fuel and in water treatment plants during the chlorination of the water [2,3]. Recent studies propose a link between disinfection practices and NDMA formations which suggests that NDMA is a water treatment and a disinfection by-product $[2,3]$. Several water agencies in California have observed the presence NDMA in drinking water supplies [2]. Choi and Valentine [2] indicate that chlorination using hypochlorite, results in the formation of approximately an order of magnitude less NDMA than chlorination using monochloramine. Mitch and Sedlak [3] and Mitch et al [4] also confirmed that the two major key precursors of concern for NDMA formation are monochloroamine and organic nitrogen compounds.

The focus for the past couple of years has been on identifying the chemical pathways and precursors that lead to the formation of NDMA during disinfection of water and wastewater. It is only recently that the focus has shifted to the investigation of cost effective removal technologies for NDMA to provide safe drinking water and reclaimed wastewater for beneficial reuse $[5,6]$. Treatment alternatives can include air-stripping, adsorption, chemical oxidation, membrane treatment, biodegradation, and UV (ultraviolet) irradiation. NDMA is a semi-volatile organic chemical and is highly soluble in water. As such air stripping and adsorption results may be poor. Fleming et al [7] reported the results of adsorption of NDMA by granular activated carbon and synthetic resins. Results indicated that the adsorption potential of NDMA was poor to the selected adsorbents. The researchers also investigated metal complexation and hydrolysis of NDMA. These methods were also not effective for NDMA removal.

The main problem in removing NDMA from drinking water is the fact that it is extremely stable in aqueous solutions. It is very resistant to biodegradation, air stripping, and absorption on activated carbon. However, irradiation with UV light shows promising results in the removal of NDMA from water [8-10].

Biodegradation of NDMA has been reported by a number of researchers. Gunnsion et al [11] reported on the aerobic and anaerobic biodegradation of NDMA in from a contaminated groundwater site. Sharp et al [12], Kaplan and Kaplan [13] and Fournier et al [14] have reported on biodegradation pathways of NDMA using pure bacterial strains. All these studies indicate that NDMA biodegradation is feasible with higher concentrations exhibiting inhibition to bacterial cultures. Pathways of NDMA biotransformation include the conversion of NDMA to NTDMA (N-nitrohydroxymethyl-methylamine), formaldehyde and formate. There is very little information on biodegradation of NDMA by mixed cultures at high concentrations.

This research focuses on an in-depth study of UV irradiation of NDMA in water and the biodegradation of NDMA using a mixed culture of microorganisms. 


\section{Materials and methods}

\subsection{Reagents}

NDMA was purchased from VWR International and used without further purification. A stock solution of NDMA was prepared using deionized water and stored in a refrigerator until needed. All other chemicals were purchased from Fisher Scientific and used without further purification.

\subsection{Experimental procedures}

\subsubsection{Photodegradation}

The photodegradation of NDMA was conducted in a Rayonet RPR-200 photochemical chamber with a merry-go-round attachment. The solutions of NDMA were exposed to sixteen $253.7 \mathrm{~nm} \mathrm{Hg}$ lamps at varying times. NDMA concentrations were determined by measuring the absorbance with the spectrophotometer at $228 \mathrm{~nm}$. After being exposed to the UV light, the samples were tested for NDMA and its intermediates. Formaldehyde and DMA were measured according to the method of Siggia [15]. Nitrate concentrations were determined using Hach method \# 8039 [16].

\subsubsection{Biodegradation}

Acclimated cultures capable of degrading NDMA were developed from wastewater obtained from the Mullica Hill Wastewater Treatment Plant at Winslow, New Jersey, USA. Enrichment cultures were developed in batch reactors incubated at room temperature with NDMA as the sole carbon source.

Batch biodegradation experiments were conducted at $20^{\circ} \mathrm{C}$ in an incubator (Model 2020, VWR, Bridgeport, NJ) using the Hach BOD Trak System (Hach, Loveland, $\mathrm{CO}$ ) with PC based data acquisition.. Oxygen uptake measurements were recorded with time. All experiments were conducted in duplicates. Nutrient buffer media was prepared using Hach BOD nutrient buffer pillow [16]. Each batch reactor was inoculated with $5 \mathrm{ml}$ of the acclimated culture with varying NDMA concentrations. Four concentrations of NDMA were tested: $35 \mathrm{mg} / \mathrm{L}, 70,140$ and $240 \mathrm{mg} / \mathrm{L}$. Experiments were conducted in duplicates and controls without NDMA and bacteria were also maintained. Experiments were conducted for twenty days.

Protein measurements were conducted for select days to determine cell growth. Protein was measured according to the method of Lowry et al [17] and bovine serum albumin was used as the protein standard. Ingraham et al [18] indicate that the cell protein is approximately $50 \%$ of dry bacterial cell mass. As such protein concentrations were doubled to obtain dry cell mass.

Chemical oxygen demand was determined at the end of the biodegradation experiments using Hach Method \# 8000 [16]. 


\section{Results and discussion}

\subsection{Photodegradation of NDMA}

The photodegradation of NDMA and formation of the by-products can be seen below in Figure 1. NDMA degraded rapidly during the first half hour of irradiation with UV light, and afterwards the rate at which it degraded became negligible. As NDMA concentration decreased, concentrations of the byproducts (DMA, formaldehyde and nitrate) increased for the first half hour. Afterwards, the concentrations of the by-products remained nearly constant. These finding are consistent with the findings of Stefan and Bolton [9].

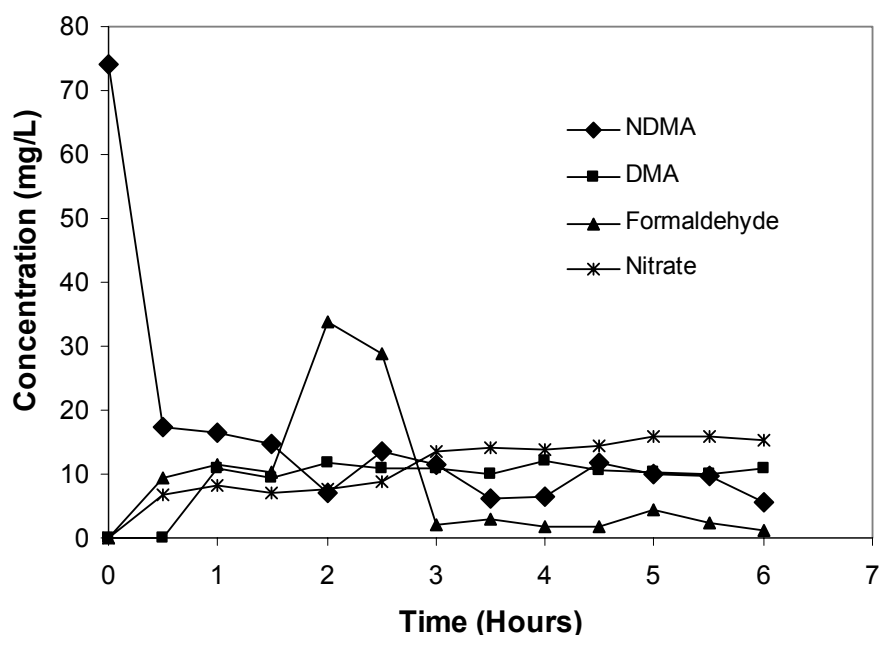

Figure 1: $\quad$ Photodegradation of NDMA at $74 \mathrm{mg} / \mathrm{L}$ and formation of byproducts.

Experiments were conducted to study the impact of $\mathrm{pH}$ changes and the addition of a catalyst on the photodegradation of NDMA. 0.015 grams of titanium dioxide was added as a catalyst to NDMA concentrations of $74 \mathrm{mg} / \mathrm{L}$. $\mathrm{pH}$ of the NDMA solutions was lowered by adding hydrochloric acid. The results of these experiments are presented in Figure 2 below. When titanium dioxide was added as a catalyst or when the $\mathrm{pH}$ was lowered, the rate of photodegradation was enhanced. It is evident that the addition of $\mathrm{TiO}_{2}$ and a lower $\mathrm{pH}$ causes more removal of NDMA from water. Results indicate that lowering $\mathrm{pH}$ or addition of $\mathrm{TiO}_{2}$ provide similar removal rates.

NDMA photodegradation rates were determined to be first order between the time intervals of 5-120 minutes. Quantum yields for the experiments were also calculated. The quantum yield parameter is the most important concept in photochemical kinetics. It is defined as follows:

$$
\phi_{D}=\frac{\text { Number of molecules reacted }}{\text { Number of photons of light absorbed }}
$$




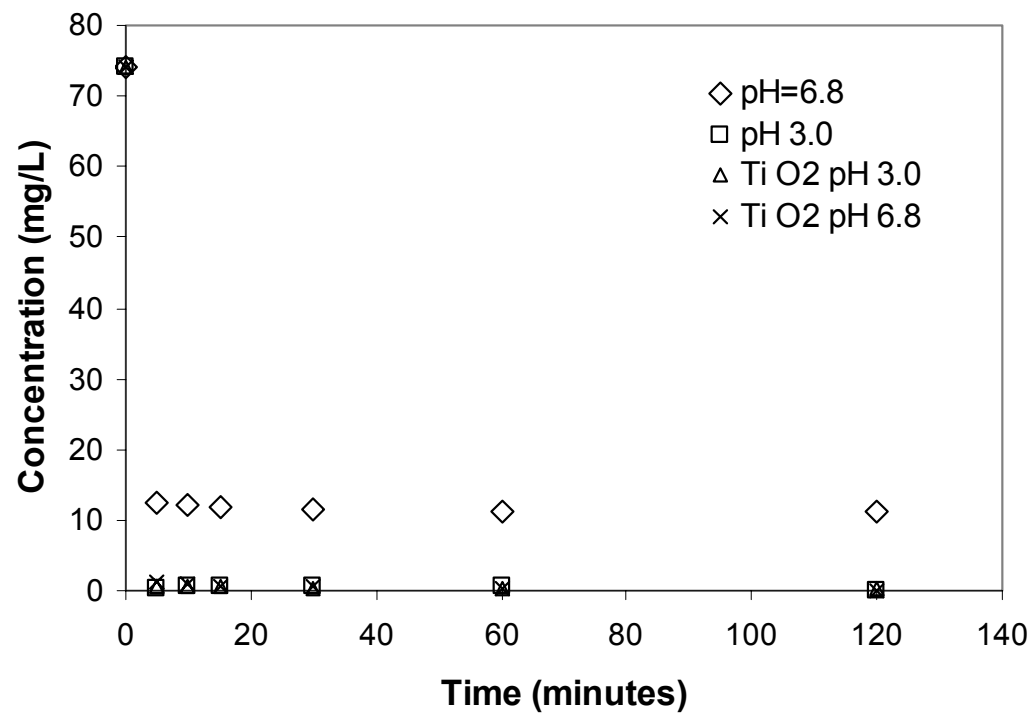

Figure 2: $\quad$ Photodegradation of NDMA at $74 \mathrm{mg} / \mathrm{L}$ at various $\mathrm{pH}$ and $\mathrm{TiO}_{2}$ concentrations.

Table 1: $\quad$ Photodegradation rates and calculated quantum yields.

\begin{tabular}{|c|c|c|}
\hline Experiment & $\mathrm{k} 1 / \mathrm{min}$ & $\Phi d$ \\
\hline $\mathrm{pH} 6.8$ & 0.0007 & 0.003 \\
\hline $\mathrm{pH} 3.0$ & 0.0093 & 0.047 \\
\hline $\mathrm{TiO}_{2} \mathrm{pH} 6.8$ & 0.0176 & 0.089 \\
\hline $\mathrm{TiO}_{2} \mathrm{pH} 3.0$ & 0.0093 & 0.047 \\
\hline
\end{tabular}

The photodegradation rate can be used to calculate the quantum yield values by using the following equation proposed by Horspool as cited by Stefan and Bolton [9].

$$
\phi_{D}=\frac{k}{2.303 \times I_{0, \lambda} \times \varepsilon_{D, \lambda} \times l}
$$

Where $\mathrm{I}_{0, \gamma}=$ intensity of the incident light at $253.7 \mathrm{~nm}\left(1.5 \times 10^{-5}\right.$ Einstein $\left.\mathrm{l}^{-1} \mathrm{~s}^{-1}\right)$

$\varepsilon_{\mathrm{D}, \gamma}=$ molar absorbtivity of NDMA at $253.7 \mathrm{~nm}\left(1 \mathrm{~mol}^{-1} \mathrm{~cm}^{-1}\right)$

$1=$ cell path length $(1 \mathrm{~cm})$

Table 1 presents the photodegradation rates for various experiments along with the calculated values of the quantum yield. 
The table indicates that addition of $\mathrm{TiO}_{2}$ at high $\mathrm{pH}$ yielded the highest photodegradation rate and quantum yield.

\subsection{Biodegradation of NDMA}

Biodegradation experiments were conducted with varying concentrations of NDMA. Oxygen uptake was measured with time with the Hach BOD Trak systems. Average oxygen uptake values of the duplicate results have been presented. Intermittent samples were obtained for protein analyses.

Chemical Oxygen Demand (COD) was calculated for the filtered contents of the reactors at the end of the experiments. CODs were determined to assess the carbon remaining in the reactors after 20 days of NDMA biodegradation.

Oxygen uptake was not observed in the controls that received only NDMA or bacteria. This eliminates abiotic removal of NDMA in the system and also confirms the negligible oxygen uptake of the mixed culture alone used in the experiments. Select results of the biodegradation experiments are presented in Figures 3. Oxygen uptake and cell growth was suppressed at the higher NDMA concentrations of 70 and $140 \mathrm{mg} / \mathrm{L}$.

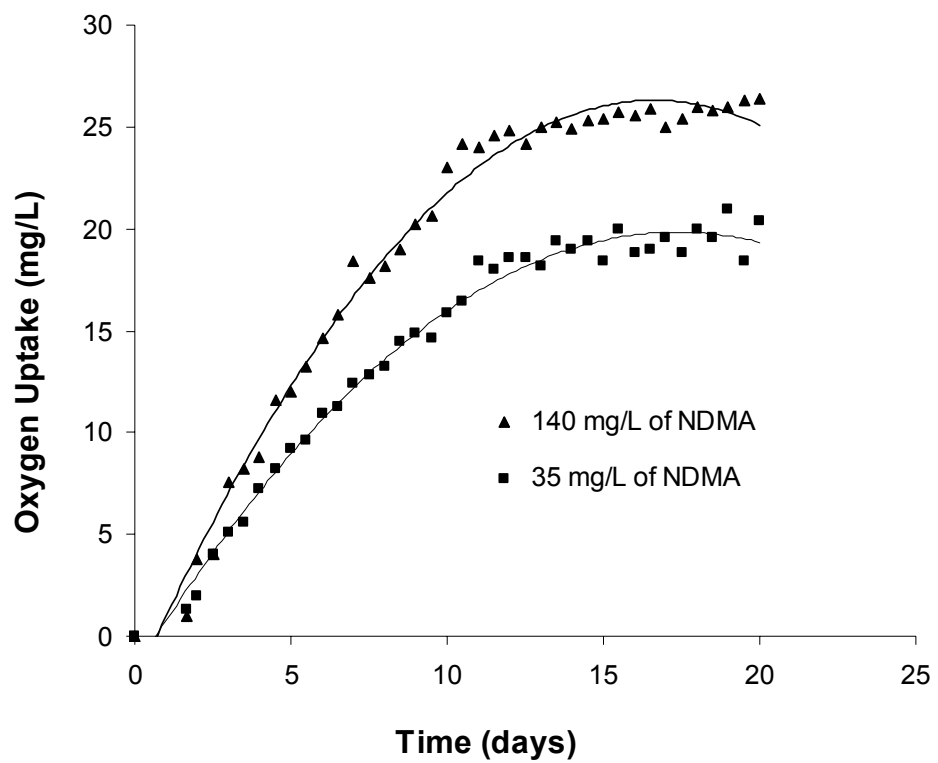

Figure 3: $\quad$ Oxygen uptake for various concentrations of NDMA.

Oxygen uptake was not observed in the reactors that received $240 \mathrm{mg} / \mathrm{L}$ of NDMA. This was an indication that either this concentration was toxic or inhibitory to the micro-organisms. In order to determine if the cells were still viable after 20 days glucose was added to stimulate growth. No oxygen uptake 
was evident for ten days after addition of glucose. This confirmed that a concentration of $240 \mathrm{mg} / \mathrm{L}$ of NDMA was toxic to the acclimated culture.

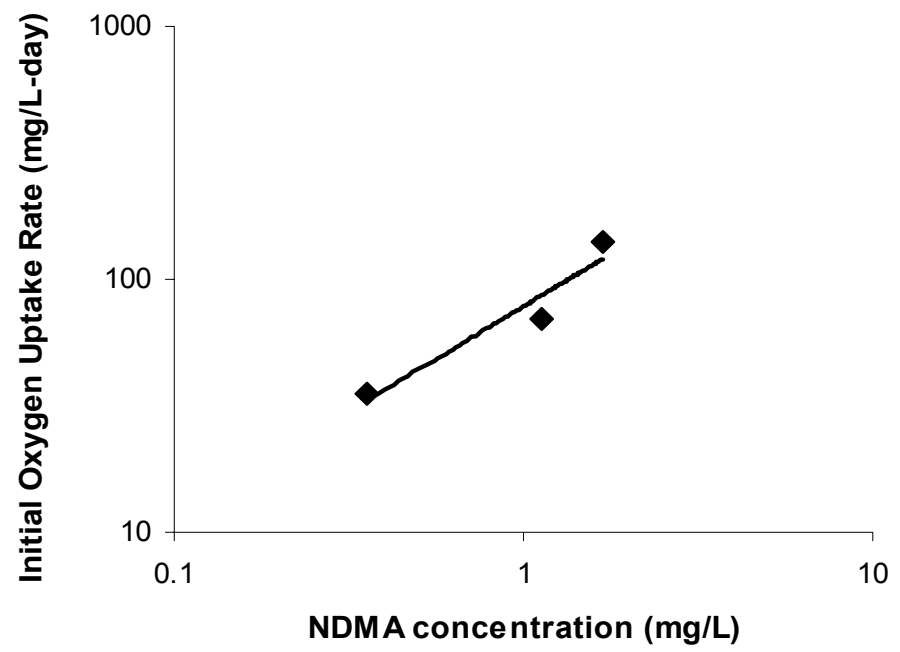

Figure 4: $\quad$ Cell Growth for various concentrations of NDMA.

The theoretical oxygen demand for NDMA biodegradation was determined using the following equation

$$
\mathrm{C}_{2} \mathrm{H}_{6} \mathrm{~N}_{2} \mathrm{O}+\frac{3}{2} \mathrm{O}_{2} \rightarrow 2 \mathrm{CO}_{2}+2 \mathrm{NH}_{3}
$$

For 35, 70, 140 and $240 \mathrm{mg} / \mathrm{L}$ of NDMA, the maximum theoretical oxygen uptake is $22.7,45.4,90.8$ and $155.67 \mathrm{mg} / \mathrm{L}$ respectively. The oxygen uptake data indicated that the $70 \mathrm{mg} / \mathrm{L}$ and $140 \mathrm{mg} / \mathrm{L}$ NDMA experiments were far less from the theoretical oxygen demand values. This could have occurred for two reasons. First NDMA biodegradation could be inhibited at the higher concentrations. However as cell growth was evidenced in these experiments, these concentrations was not deemed toxic. It is also unclear if the formation of intermediates such as DMA, formaldehyde and dimethylhydrazine may have been the cause of inhibition as opposed to the NDMA compound alone. Biodegradation intermediates were not measured during these experiments. Literature indicates the formation of these intermediates during the aerobic biodegradation of NDMA [13]. The second reason could be the need for more acclimation of the culture to the intermediates. If the experiments were run for longer periods of time biodegradation may have progressed.

The COD results at the end of the experiment as presented in Table 2 below:

The table indicates that NDMA or its intermediates were only partially degraded at the higher concentrations of 70, 140 and $280 \mathrm{mg} / \mathrm{L}$. This partial degradation could have been due to inhibitory reactions from NDMA or its intermediates. 
Table 2: $\quad$ Filtered COD values at end of experiment.

\begin{tabular}{|c|c|}
\hline $\begin{array}{c}\text { NDMA Concentration } \\
\mathrm{mg} / \mathrm{L}\end{array}$ & COD mg/L \\
\hline 35 & 1.67 \\
\hline 70 & 15.2 \\
\hline 140 & 33.5 \\
\hline 240 & 61.3 \\
\hline
\end{tabular}

Initial oxygen uptake rates were obtained for the initial linear part of the oxygen uptake curves and are presented in Table 3.

Table 3: $\quad$ Initial $\mathrm{O}_{2}$ uptake rates.

\begin{tabular}{|c|c|}
\hline NDMA Concentration, mg/L & Initial Oxygen Uptake Rate mg/L-day \\
\hline 35 & 0.356 \\
\hline 70 & 1.12 \\
\hline \hline 140 & 1.68 \\
\hline
\end{tabular}

This rate data was further analysed using Michaelis-Menten enzyme kinetics [19]. Log-log plots of the initial rates versus initial concentration of NDMA were used to fit both linear and non linear least-squares models to the data. The linear model gave a better fit for the data. This is presented in Figure 4.

The log-log plot in Figure 4 has a slope almost equal to 1 which is a reflection that the substrate concentrations are below $\mathrm{K}_{\mathrm{m}}$ which is the concentration of substrate that leads to half-maximal velocity as defined in the Michaelis-Menten model. The slope of this linear model also represents the order of the reaction and in this case this is first order.

The same behaviour was observed by Kaplan and Kaplan [13] for NDMA in the concentration ranges of 15 to $1.22 \times 10^{-5} \mu \mathrm{g} / \mathrm{mL}$. These authors concluded that the rate of NDMA mineralization was concentration dependent at the select NDMA concentrations.

\section{Conclusions}

Batch experiments on NDMA photodegradation and biodegradation by a mixed culture were carried out. Photodegradation experiments indicated that NDMA can be rapidly photodegraded. The photodegradation process was enhanced at low $\mathrm{pH}$ and in the presence of titanium dioxide. Biodegradation experiments indicate that acclimated enrichment cultures can be easily cultivated from municipal wastewaters. These cultures needed very little acclimation period to 
NDMA. Inhibitory effects were observed during biodegradation experiments with the higher NDMA concentrations.

\section{References}

[1] Mezyk, S.P., Cooper, W.J., Madden, K.P. \& Bartels, D.M., Free Radical Destruction of N-Nitrosodimethylamine (NDMA) in Water. Environmental Science and Technology. 38, pp. 3161-3167, 2004.

[2] Choi, J. \& Valentine, R.L., Mechanistic studies of N-Nitrosodimethylamine (NDMA) formation in chlorinated drinking water. Journal of Environmental Monitoring. 4, pp. 249-252, 2002.

[3] Mitch, W.A. \& Sedlak, D.L., Formation of NDMA from Dimethylamine during Chlorination, Env. Sci. Technol. 36(4), pp. 588-595, 2002.

[4] Mitch, W.A., Gerecke, A.C. \& Sedlak, D.L., A NDMA precursor analysis for chlorination of water and wastewater, Water Research, 37, pp. 37333741, 2003.

[5] Shiaw-Jy Huitric, Kuo, J., Tang, Chi-Chung, Creel, M., Horvath, R. \& Stahl, J., Fate of NDMA in tertiary water reclamation plants, Proc. Technology 2005 2nd Joint Specialty Conference for Sustainable Management of Water Quality Systems for the $21^{\text {st }}$ Century, San Francisco, CA, Aug. 28 Aug 31, 2005.

[6] Haruta, S., Chen, W., Gan, J., Simunek, J., Chang, A.C. \& Wu, L., Leaching risk of NDMA in soil receiving reclaimed wastewater, Ecotoxicology and Environmental Safety, In Press.

[7] Fleming, E.C., Pennington, J.C., Wachob, B.G., Howe, R.A. \& Hill, D.O., Removal of NDMA from waters using physical-chemical techniques, $J$. Haz. Was. Mat, 51, pp. 151-164, 1996.

[8] Sharpless, C.M. \& Linden, K.G., Experimental Comparisons of low and medium pressure mercury lamps for the direct and $\mathrm{H}_{2} \mathrm{O}_{2}$ assisted photodegradation of N-NDMA in simulated drinking water. Environmental Science and Technology. 37, pp. 1933-1940, 2003.

[9] Stefan, Mihaela I. and Bolton. James R., UV Direct Photolysis of $\mathrm{N}$ Nitrosodimethylamine (NDMA): Kinetic and Product Study. Helvetica Chimica Acta. 85, pp. 1416-1426, 2002.

[10] United States Environmental Protection Agency. Handbook on Advanced Photochemical Oxidation Processes. EPA/625/R-98/004. December 1998.

[11] Gunnison, D., Zappi, M.E., Teeter, C., Pennington, J.C. \& Bajpai, R., Attenuation mechanisms of NDMA at an operating intercept and treat groundwater remediation system, J. Haz. Was. Mat, B73, pp. 179-197, 2000.

[12] Sharp, J.O., Wood, T.K. \& Cohen, L., Aerobic biodegradation of NDMA by axenic bacterial strains. Biotechnology and Bioengineering. 89(5), pp. 608-618, 2005.

[13] Kaplan, D.L. \& Kaplan, A.M., Biodegradation of N-Nitrosodimethylamine in aqueous and soil systems. Applied and Environmental Microbiology, 50(4), pp. 1077-1086, 1985. 
[14] Fournier, D., Hawari, J., Streger, S. H., McClay, K. \& Hatzinger, P.B., Biotransformation of N-Nitrosodimethylamine by Pseudomonas Mendocina KR1. Applied and Environmental Microbiology. pp. 66936698, 2006.

[15] Siggia, S., Instrumental Methods of Organic Functional Group Analysis. New York: John Wiley \& Sons Inc, 1972.

[16] http: ॥www.hach.com

[17] Lowry, O.H., Rosebrough, N.J., Farr, A.L. \& Randall, R.J., Protein measurements with the Folin Phenol Reagent. J. Biol. Chem. 193, pp. 265$275,1951$.

[18] Ingraham J.L., Maaloe, O. \& Neidhardt, F.C., (1983) Growth of Bacterial Cell. Sinauer Associates Inc., Sunderland, MA.

[19] Briggs, G.E. \& Haldane, J.B.S., A note on the kinetics of enzyme action, Biochem. J., 19, pp. 338-339, 1925. 